\title{
PROCESOS DE APROPIACIÓN ADOLESCENTE DEL ESPACIO PÚBLICO: OTRA CARA DE LA RENOVACIÓN URBANÍSTICA EN BARCELONA ${ }^{1}$
}

\author{
Anna Ortiz Guitart, Maria Prats Ferret y Mireia Baylina Ferré \\ Departamento de Geografía. Universitat Autònoma de Barcelona \\ anna.ortiz@uab.es, maria.prats@uab.es, mireia.baylina@uab.es
}

\section{RESUMEN}

Este artículo presenta el papel de la edad como eje de análisis en el marco de la geografía social y cultural. El trabajo de campo incluye grupos de discusión, entrevistas individuales e itinerarios participativos por el barrio, para identificar cuáles son los lugares frecuentados, los lugares preferidos y los lugares evitados por este grupo de población. Nos interesa conocer como desarrollan su vida en el barrio, como ocupan su tiempo cotidiano y como utilizan los espacios públicos. Analizar la vida en el barrio es esencial para entender las diferentes necesidades e intereses de chicos y chicas en relación a sus experiencias y percepciones de los espacios vividos.

Palabras clave: adolescencia, espacio público, renovación urbana, género, Barcelona.

\section{ABSTRACT}

This article presents the role of age as an important axis of analysis in the framework of social and cultural geography. The fieldwork includes focus groups, interviews and walking tours around the neighborhood, to identify the more used places, the preferred places and the places young people don't like. We want to know how they build their lives in the neighborhood, how they spend their time and how they use public spaces. Analyzing the neighborhood life is essential to understand the different needs and interests of boys and girls in relation to their experiences and perceptions of lived spaces.

Key words: young people, public space, urban renewal, gender, Barcelona.

Fecha de recepción: mayo 2012.

Fecha de aceptación: junio 2013.

1 Esta investigación ha sido financiada por el Institut Català de les Dones (Ref. U-119/10) y la Agència Catalana de la Joventut (Ref. AJOVE20100003) de la Generalitat de Catalunya (2010-2012). 


\section{LAS GEOGRAFÍAS DE LA INFANCIA Y LA JUVENTUD: APROXIMACIONES TEÓRICAS Y CONCEPTUALES}

La mayor parte de la juventud actual crece, aprende, goza y trabaja en ciudades. En la medida que las personas jóvenes viven estos espacios contribuyen a su materialización, sus experiencias cotidianas forman parte del conjunto de relaciones que se desarrollan en la ciudad y a la vez éstas se explican por las estructuras y las prácticas sociales y espaciales de cada ciudad en particular. Así, dependiendo de cada localización geográfica, la juventud participará en la vida urbana con sus actividades con más o menos límites y desafiará en mayor o menor grado los usos excluyentes del espacio urbano (Hörschelmann y van Blerk, 2011). Conocer y comprender la vida de los y las jóvenes en la ciudad nos permite acercarnos más a ellos, conocer la ciudad que contribuyen a crear y adentrarnos en las relaciones de poder y jerarquías sociales que conlleva la categorización por edad.

Desde los años setenta en que geógrafos como Ward (1978) criticaban el hecho que la ciudad existía solamente para un tipo particular de personas: hombre, adulto, trabajador calificado, usuario de coche particular, los estudios sobre las experiencias y contribuciones de otros grupos sociales en el espacio urbano se han desarrollado de forma muy fructífera (los estudios de género o de etnicidad, por ejemplo). Entre ellos también destacan los estudios sociales sobre infancia y juventud, que muy pronto inspiran a los geógrafos/as hasta el punto de consolidar una línea de investigación que, desde hace veinte años, ha producido un volumen muy importante de trabajos, básicamente en el ámbito anglosajón.

Las geografías de la infancia y la juventud se desarrollan con la finalidad de incluir la diversidad de experiencias y necesidades de aquellas personas que, por su edad, género, sexualidad, etnia, clase o discapacidad han quedado tradicionalmente excluidas de los estudios geográficos (Aitken, 1994, 2001; Holloway y Valentine, 2000; McKendrick, 2000; Ortiz, 2007; Prats, 2010; Rodó-de-Zárate, 2010). A lo largo de estos años, se han tratado numerosos temas dejando un importante legado de investigaciones que han enfatizado la capacidad de acción de niños, niñas y jóvenes en distintos aspectos tratados por la geografía (Mathews, 2003; Katz, 2006; Holloway, Brown y Pimlott-Wilson, 2011). Entre estos estudios destacan los que hacen referencia al análisis de la vida cotidiana de los niños, niñas y jóvenes en relación a su presencia y uso de los espacios públicos urbanos (Matthews, 1995; Percy-Smith y Matthews, 2001; Churchman, 2003; Karsten, 2003; Blackford, 2004; Valentine, 2004; Baylina, Ortiz y Prats, 2006).

Los conceptos de infancia, adolescencia y juventud son complicados de definir y las franjas de edad que a menudo se utilizan varían según quién lo defina. Aspectos como las fases de desarrollo en sentido biológico y psicológico, la dependencia, la necesidad de protección, la adquisición de autonomía o la construcción de las propias identidades, entre otras, conforman los discursos sobre quién es niño/a, adolescente o joven. Lo que resulta claro es que son conceptos socialmente construidos, no universales e históricamente y culturalmente variables. Las importantes diferencias culturales, de clase y de género hacen que su significado y sus fronteras sean ambiguas y cambiantes en el espacio y en el tiempo (Boratav, 2005; Evans, 2006). Por su parte, el espacio público se ha considerado, en estas investigaciones, como un lugar culturalmente construido, un producto de la sociedad y con una importante función social (Lieshout y Aarts, 2008) tanto en relación 
a su capacidad de construcción de la diferencia, la semejanza y la identidad como porque su acceso es una condición necesaria para el ejercicio de la ciudadanía (Ehrkamp, 2008).

Son numerosos los estudios realizados sobre la relación de la juventud con el espacio público urbano destacando la relevancia que tiene la calle para la gente joven, como lugar de autonomía, de construcción de identidades personales y colectivas (Gough y Franch, 2005), de desarrollo de sus amistades (Bunnell et al., 2012); o también como lugar donde afrontar las imposiciones reguladoras de los adultos (Mattews, Taylor, Percy-Smith y Limb, 2000). El espacio público resulta ser un espacio de no supervisión y de libertad que permite el encuentro con otras personas de forma no controlada, o por lo menos no al mismo nivel que dentro del hogar. Ahora bien, este supuesto espacio de libertad colisiona con la llamada adultificación del espacio público, o el hecho por el cual el espacio público urbano está construido por y para personas adultas, y producido como un espacio público adulto (Driskell, Fox y Kudva, 2008). Este hecho, añadido a la concepción que se tiene sobre los y las jóvenes, como personas a proteger y/o como una amenaza, hace que a menudo la gente joven sea excluida del espacio público o no sea siempre bienvenida (Rodó-de-Zárate, 2010). Aun así, la calle y el espacio público en general tiene un papel fundamental en la juventud como lugar de aprendizaje y de construcción del yo (Holloway, Hubbard, Jöns y Pimlott-Wilson, 2010). Sin embargo, la presencia en la calle no es la misma para una chica que para un chico. El patriarcado determina unos roles para cada género y disciplina los cuerpos a fin que se comporten de una forma adecuada en el espacio público (Rodó-de-Zárate, 2010). Por lo tanto, el uso del espacio público y la experiencia del mismo en el barrio o en la ciudad variarán en función del género, y los significados que ellos y ellas otorguen a los espacios también podrán ser distintos.

En este contexto, la adolescencia es la etapa menos estudiada de las geografías de la infancia y la juventud, a pesar de que lo que se ha dicho sobre estos dos colectivos no siempre representan las experiencias de vida de los y las adolescentes (Weller, 2006). Igualmente ha existido una tendencia a construir el comportamiento y las prácticas espaciales de las chicas y chicos adolescentes como universales de acuerdo con las perspectivas de los debates dominantes del mundo occidental minoritario, influyendo en los discursos y las prácticas políticas de otros contextos (Skelton, 2011). Además, cuando se habla de adolescencia, sobre todo en los medios de comunicación, a menudo se le atribuyen connotaciones negativas estigmatizando esta etapa vital como impregnada de comportamientos antisociales.

Los y las adolescentes se sitúan en medio de los niños/as y los/as jóvenes. Un/a adolescente puede ser un niño/a, un/a joven o una persona adulta, o estar en medio de cualquier de estas categorías. Se trata de una etapa de transición, necesaria y confusa para los/as jóvenes en la que se debaten entre el deseo de aferrarse a la protección que reciben siendo niños y niñas y el de ejercer ya los derechos como personas adultas. Lo que quizás identifica a los y las adolescentes al margen de la edad es fundamentalmente un aumento de la independencia y el hecho de no estar tan vigilados por familiares adultos, tanto en casa como fuera de ella (Weller, 2006). En nuestro contexto, el paso de la educación primaria a la educación secundaria obligatoria (12 años) supondría un condicionante importante para una mayor adquisición de autonomía por parte de los y las adolescentes ya que implica, en muchos casos, un cambio de escuela y de modelo educativo, menos supervisado. Cahill (2000) reivindica los estudios de la adolescencia ya que es en esta etapa que se producen los principales ritos de transición de la juventud (primeras responsabilidades reales, experiencias laborales, expe- 
riencias sexuales...), y la primera negociación del espacio público por su cuenta de forma habitual, sin ir acompañados/as de una persona adulta. La misma autora crea el concepto de 'alfabetización de calle' o marco interpretativo que privilegia los conocimientos locales informales que se basan en las experiencias personales en un contexto específico, el espacio público urbano. Según la autora, el entorno, y la calle en particular, es un contexto significativo para aprender a fin de explorar las relaciones de la juventud con el barrio. Y en este contexto, los y las adolescentes tienen mucho conocimiento de los protocolos del entorno y adquieren competencias ambientales de negociación a escala de barrio, que han aprendido de sus experiencias con sus padres, madres, otros adultos y otros/as jóvenes (Cahill, 2000).

En esta línea, se han realizado algunos estudios que tratan la interacción de los y las adolescentes con el espacio público focalizando en el tiempo libre (Vanderstede, 2011), en el uso y la representación en los espacios de consumo (Matthews, Taylor, Percy-Smith y Limb, 2000; Thomas, 2005; Kato, 2009), las redes de amistad (Reynolds, 2007; Giró, 2011) o reflexiones acerca de sus subjetividades y los discursos sobre la adolescencia (Raby, 2002). $\mathrm{Y}$ algunas lo hacen desde una clara perspectiva feminista tratando la diversidad de chicas adolescentes y su comportamiento en el espacio público en función de su etnia, clase o sexualidad (Hyams, 2003; Morris-Robert, 2001; 2010).

En este artículo se pretende dar a conocer cómo chicas y chicos adolescentes (14 y 15 años) ${ }^{2}$ del barrio Besós-Maresme de Barcelona desarrollan su vida en el barrio, en particular cómo utilizan su tiempo y espacio en este entorno cotidiano. Entendiendo que su actividad central es el estudio, que realizan en el centro educativo y que les ocupa la franja central del día, se analizan cuáles son sus actividades y experiencias fuera del horario y ámbito escolar. Con este propósito, nos preguntamos qué ofrece el barrio/la ciudad a los/as adolescentes, que es lo que ellos/as utilizan y de qué manera. En este sentido consideramos a los y las adolescentes del Besós de Barcelona como un grupo social construido en relación a la edad pero también en base a relaciones sociales específicas y a las interacciones de la cultura, la política y las estructuras institucionales en el momento de desarrollar la investigación.

A continuación se exponen las características del área de estudio, el barrio del BesósMaresme de Barcelona y la metodología utilizada. Seguidamente se analizan los principales resultados de la investigación y al final se apuntan las conclusiones más relevantes así como algunas ideas para investigaciones futuras.

\section{EL BARRIO DEL BESÓS-MARESME DE BARCELONA}

El barrio tiene una población de 24.403 habitantes y una extensión de 1,3km². La estructura de edades de su población es muy parecida a la media de Barcelona, contando con un $12,5 \%$ de población menor de 14 años y de un 18,3\% de población mayor de 65 años. La presencia de población extranjera es significativa, representa un 28,8\%, 10 puntos por encima de la proporción en la ciudad (18,1\%) (Ayuntamiento de Barcelona, 2010). El barrio, situado en el noreste de la ciudad, está considerado como uno de los barrios más pobres de Barcelona (según cifras de renta familiar disponible per cápita) (Recio, 2008).

2 Excepcionalmente algún estudiante tiene 16 años por haber repetido un curso o por una incorporación tardía al curso académico. 
Figura 1

LOCALIZACIÓN DEL DISTRITO Y EL BARRIO EN BARCELONA

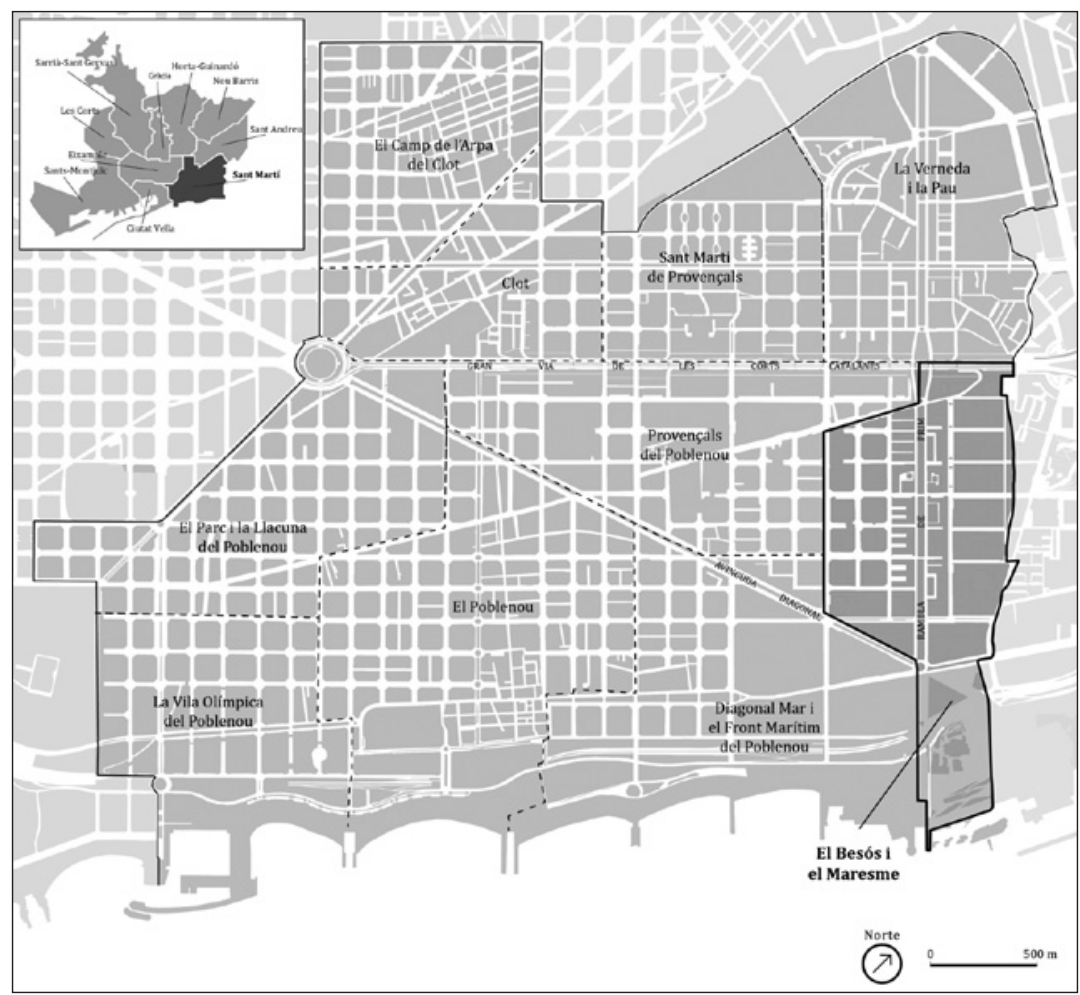

Fuente: Elaboración del mapa realizada por Alfons Parcerisas.

El barrio Besós-Maresme, situado en el distrito de Sant Martí, a pesar de las dos denominaciones, es un solo barrio estadísticamente y administrativamente hablando (Figura 1). El Besós y el Maresme, divididos físicamente por la Rambla Prim, son áreas con orígenes distintos ${ }^{3}$. El Besós se construyó en los años cincuenta y sesenta del siglo $\mathrm{xx}^{4}$, sobre campos de cultivo, para dar respuesta al déficit de viviendas que había en Barcelona como consecuencia de la llegada de población inmigrante del sur de España, mayoritariamente. Durante los primeros años las carencias urbanísticas del barrio, así como la falta de servicios y equipamientos (pésima calidad de los materiales usados en la construcción de los bloques de pisos y falta de escuelas, de centros sanitarios, de espacios verdes, de transporte público) influyó muy negativamente en la calidad de vida de las personas del barrio y fue gracias a las reivindicaciones vecinales -como también sucedió en otros barrios de la peri-

3 El Besós está delimitado por la rambla Prim, la Gran Vía, el río Besós y el mar. Y el Maresme es un rectángulo estrecho delimitado por la rambla Prim, la Gran Vía, la calle Llull y la calle del Maresme.

4 Concretamente, en el año 1959 el patronato Municipal de la Vivienda empezó a edificar el polígono de viviendas. 
feria de Barcelona- que las mejoras fueron sucediéndose lenta pero paulatinamente ${ }^{5}$. Si el Besós se construyó por iniciativa pública, el del Maresme se levantó por iniciativa privada entre 1954 y 1964 aprovechando la gran demanda de viviendas provocada por la inmigración y se erigió sobre campos alrededor de un centenar de casas bajas construidas en los años veinte ${ }^{6}$ (Alberch, 2000).

Las transformaciones urbanísticas del barrio ocurridas en las últimas décadas han sido espectaculares. Si un gran acontecimiento deportivo como los Juegos Olímpicos en 1992 sirvió de excusa para transformar parte de la franja litoral del levante de la ciudad, dando como resultado la creación del barrio de la Vila Olímpica y la mejora de las playas; otro acontecimiento, en este caso cultural, como fue el del Fórum Universal de las Culturas 20047, continuó la transformación hacia el este animando a crear un nuevo barrio, el de Diagonal Mar, y revitalizó todo su entorno. Este nuevo barrio es colindante con el Besós-Maresme y, de esta forma, bloques de viviendas de estructuras antiguas conviven con rascacielos y hoteles de alto nivel; además de que el barrio ha incorporado en su paisaje el parque de Diagonal Mar (diseñado por los arquitectos Enric Miralles y Benedetta Tagliabue) ${ }^{8}$, el centro comercial de Diagonal Mar, y el espacio público del Fórum ${ }^{9}$ construidos a principios del siglo XXI.

Sin embargo, y como señala Borja (2010), mientras que la construcción de la Vila Olímpica no planteó ningún problema de integración con la ciudad ni provocó una reacción social negativa, las operaciones de Diagonal Mar y del Fórum resultaron polémicas porque suponían una ruptura con el urbanismo «democrático», llevada a cabo hasta el momento, que promovía la mixtura social y funcional. Diagonal Mar recibió fuertes críticas de los movimientos vecinales y profesionales ya que era una operación basada en «torres aisladas, sin continuidad de construcción y con espacios abiertos a la nada, de escasa vida ciudadana» (Borja, 2010: 99), y el Fórum, no fue un acontecimiento del todo exitoso aunque permitió la construcción de un gran espacio público en una área de la ciudad tradicionalmente olvidada.

5 Algunos datos significativos: 1) No es hasta el año 1982 que el metro llega al barrio y acerca éste al resto de la ciudad. 2) En 1990 termina de urbanizarse la rambla Prim, un descampado ocupado por torres de alta tensión. Actualmente, es uno de los ejes vertebradores del barrio. 3) No es hasta el año 1993 que se inaugura el Centro Cívico, un espacio de encuentro social y cultural para los vecinos/as del barrio.

6 Los libros de Fabré y Huertas (1977) y AAVV (1994) resultan imprescindibles para conocer los orígenes, la evolución y la identidad del barrio.

7 La celebración del Fórum Universal de las Culturas 2004 estuvo teñida por el escepticismo y las críticas posteriores de buena parte de la ciudadanía de Barcelona. La paz, el desarrollo sostenible y la diversidad cultural fueron los ejes principales del evento cultural y para los anti-fórum fueron «prostituidos (...) para maquillar una operación urbanística y económica gestionada de forma mercenaria". La plataforma criticó la renovación urbanística de la zona porque "en la práctica, supone una sustitución social de los barrios en favor de las élites económicas" ya que, antes de comenzar el evento, "los precios de las viviendas de la zona ya habían subido un 50\%" (Indymedia Barcelona, 2004).

8 El parque tiene una superficie de 14 hectáreas, está perfectamente integrado con la trama urbana y cuenta con numerosos caminos, áreas de reposo, estructuras decorativas y un gran lago interior. Este parque fue construido en el antiguo solar de la fábrica Macosa (una fábrica metalúrgica que fabricaba vagones de tren y metro). El 21 de septiembre de 2002 la noticia en El País que informaba sobre la finalización de las obras del parque de Diagonal Mar llevaba por título «Un parque para dos caras de la Diagonal», mostrando, así, la distinta realidad urbanística y social a ambos lados de la avenida Diagonal (Cia, 2002).

9 En el espacio donde actualmente se localiza el Fórum de las Culturas 2004 se utilizaba durante la dictadura franquista como lugar de fusilamiento y desde los años cuarenta hasta los ochenta fue un barrio de barracas conocido como el Camp de la Bota. 
Para este urbanista, la operación fue polémica pero la opción de crear una área de nueva centralidad (a partir sobre todo de hoteles y oficinas de alto nivel) en una zona marginal fue una decisión valiente. En la misma línea, Domènech (2006: 41) critica también la transformación urbanística como consecuencia del Fórum y apunta que: «la ciudad necesita sus ritmos propios, más ligados al esfuerzo de la vida cotidiana (...) que a la inversión de dinero y de proyectos sobre un acontecimiento puntual».

Solamente se podrá considerar que estas nuevas actuaciones, el barrio de Diagonal Mar y el Fórum, han valido la pena cuando el nuevo tejido se integre con el entramado del viejo barrio popular e industrial, el del Besós-Maresme; y estas áreas tan distintas sociológicamente y urbanísticamente hablando, sólo podrán articularse cuando mejore substancialmente la calidad urbanística del barrio del Besós-Maresme. En relación con este punto cabe decir que en el año 2009 y dentro de la Ley de Barrios ${ }^{10}$, este barrio fue escogido para recibir ayudas de la administración para efectuar, en el período 2008-2012, actuaciones destinadas a la rehabilitación de las viviendas más degradadas, a la renovación del espacio público, la dotación de más equipamientos públicos, así como la puesta en marcha programas de atención social y de impulso del tejido comercial.

Es en este contexto urbano de grandes contrastes donde se inscribe la vida cotidiana de los chicos y chicas del Besós-Maresme. La integración entre el antiguo barrio y las nuevas construcciones, que los urbanistas señalaban como imprescindible para reconocer bondades en las intervenciones, emerge como una práctica cotidiana por parte de las nuevas generaciones. Aquí es necesario señalar que nuestra investigación no adoptó los límites físicos administrativos del barrio sino lo que ellos consideraron como tal.

\section{UNA APROXIMACIÓN METODOLÓGICA CUALITATIVA E INCLUSIVA}

El trabajo de campo se llevó a cabo durante los años 2010 y 2011 en un instituto público de secundaria del barrio del Besós-Maresme de Barcelona con alumnos/as de $3^{\circ}$ y $4^{\circ}$ de ESO, de edades comprendidas entre los 14 y 15 años. Con el fin de incentivar la participación, de aproximarnos a los alumnos desde distintas ópticas y darles la oportunidad de expresarse de distintas formas (de forma escrita, oral y visual), se utilizaron tres técnicas cualitativas distintas: grupos de discusión, entrevistas semi-estructuradas e itinerarios participativos por el barrio. Las dos primeras técnicas se desarrollaron en aulas cedidas por el mismo instituto y la tercera se desarrolló en el exterior y por el mismo barrio del Besós-Maresme. El trabajo de campo se llevó a cabo durante semanas lectivas y nuestras propuestas de actividades fueron incluidas como actividades culturales en las programaciones del instituto. Además de diversas visitas exploratorias por el barrio, se entrevistó a personal docente del instituto, a los dos presidentes de las asociaciones de vecinos de Besós y Maresme y a personal cualificado del centro cívico del barrio con el fin de conocer mejor el contexto urbano y social de los adolescentes en el barrio.

10 El objetivo fundamental de las ayudas que reciben los barrios a partir de la Ley de Barrios es frenar la degradación de los barrios, mejorar las condiciones de la población residente y favorecer la cohesión social (Ayuntamiento de Barcelona, 2009). 
La primera actividad se llevó a cabo con 40 adolescentes y consistió en la organización de 4 grupos mixtos de discusión (de aproximadamente 10 personas por grupo). Reunidos alrededor de una mesa y con las tres investigadoras presentes en el aula ${ }^{11}$, se les explicó los objetivos del trabajo y se les agradeció de antemano su participación. Se les pidió que rellenasen unas fichas con algunos datos personales (nombre con seudónimo para preservar el anonimato y edad) y unas preguntas relacionadas con sus usos cotidianos en el barrio. Posteriormente, y frente a un mapa de la zona, se les pidió que cada uno señalase con distintas etiquetas de colores sus lugares más frecuentados, los preferidos y los evitados por cualquier motivo, así como su lugar de residencia (Figura 2). Esta dinámica nos permitió obtener un mapa de conjunto para iniciar una discusión sobre sus vivencias y experiencias en el barrio. En los cuatro grupos los debates fueron intensos y muy animados, creándose un ambiente agradable para expresar cualquier tipo de comentario. Al final de la sesión, de aproximadamente una hora, se les pidió valorar la actividad y les pedimos que nos indicasen si les gustaría seguir participando con la investigación en las fases posteriores (entrevistas individuales e itinerarios participativos).

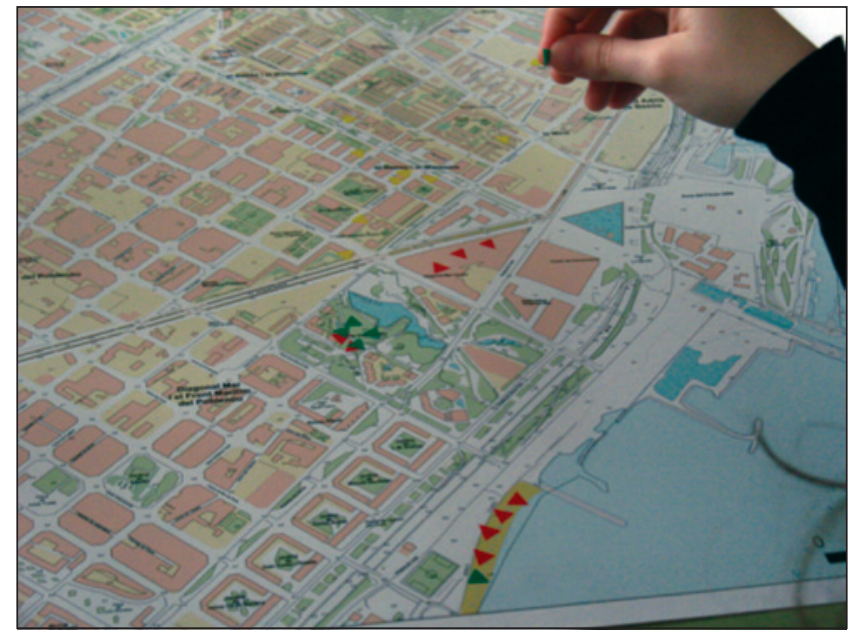

Fuente: Fotografía tomada por Anna Ortiz.

La segunda actividad con los adolescentes consistió en la realización de entrevistas semi-estructuradas. Se realizaron un total de 28 entrevistas (17 chicas y 11 chicos), cinco de ellos nacidos en el extranjero ${ }^{12}$. Las preguntas giraron en torno a sus activida-

11 En todos los grupos de discusión estuvimos presentes las tres investigadoras, pero sólo una intervenía como moderadora del debate y las otras dos observábamos y hacíamos fotografías de la actividad. Estas fotografías respetan en todo momento la normativa sobre privacidad del centro.

12 De estos cinco alumnos extranjeros entrevistados: dos chicos son nacidos en Perú y tres chicas son nacidas en Nepal, Pakistán y la República Dominicana, respectivamente. En el instituto de secundaria donde estudian el 25\% del alumnado es de origen extranjero. 
des diarias (en el instituto, en el barrio y en su casa), sus amistades, sus valoraciones y experiencias en el barrio (uso de los espacios públicos, lugares frecuentados, movilidad y autonomía personal), sus opiniones sobre los cambios urbanísticos vividos por el barrio, su conocimiento de Barcelona y sus expectativas de futuro. Todas las entrevistas se desarrollaron en un ambiente relajado, tuvieron una duración de entre 30 y 45 minutos aproximadamente y fueron grabadas, transcritas y, posteriormente, codificadas a partir de unas palabras claves.

La tercera actividad permitió observar directamente todo aquello que se había debatido y expresado previamente en las aulas. Se realizaron un total de 9 itinerarios participativos en los que los chicos y chicas, agrupados en grupos de entre 3 y 4 personas y acompañados por un investigador/a, recorrieron libremente el barrio mostrando los espacios más significativos relacionados con sus experiencias cotidianas. Durante aproximadamente una hora y media los adolescentes guiaron el recorrido, comentando lo observado y haciendo fotografías de todo aquello que deseaban mostrar por alguna razón. Paralelamente, se señalaba en un mapa el recorrido y se grababan las descripciones y comentarios que los adolescentes hacían para posteriormente ser transcritos y analizados. Esta técnica permitió aflorar imágenes, impresiones y críticas no aparecidas anteriormente en los grupos de discusión o en las entrevistas individuales, propiciar el dialogo espontáneo entre ellos/as y la investigadora, así como, inducir a los chicos y chicas a nuevas reflexiones sobre los espacios de su cotidianidad.

Al finalizar la etapa del trabajo de campo, se presentaron los resultados de la investigación a los alumnos que colaboraron en todas las fases de ésta y a los profesores del instituto. La presentación se hizo en la sala de actos del centro y consistió en la proyección de los principales resultados amenizados con música y fotografías del barrio realizadas por ellos durante los itinerarios participativos. Esta actividad se realizó para agradecer la participación de los alumnos/as y recibir sus impresiones sobre los resultados.

\section{APROPIACIÓN Y USO COTIDIANO DEL ESPACIO PÚBLICO}

El estudio de la vida cotidiana y la relación de las personas con los espacios en los que viven es un tema muy amplio y transversal porque entrelaza varias dimensiones espaciotemporales: la educación, la familia, la amistad, el barrio, la identidad, el sentido de lugar, etc. La vivencia cotidiana de estos chicos y chicas adolescentes en los espacios del barrio del Besós-Maresme de Barcelona puede no ser muy diferente de la que experimentan otros adolescentes de otros barrios populares, en Barcelona o en cualquier otro lugar de España. Ahora bien, al mismo tiempo podemos decir que se trata de una vivencia única por cuanto esas vidas cotidianas se desarrollan en un contexto geográfico concreto, caracterizado por recientes y fuertes transformaciones urbanísticas, generadoras de nuevas oportunidades y de nuevos espacios.

Los resultados del trabajo de campo presentan y analizan cuáles son los lugares del barrio que se tornan relevantes para la cotidianidad de estas chicas y chicos adolescentes, contribuyen a su inclusión social y a su calidad de vida. Estos lugares son relevantes por ser los lugares donde desarrollan sus actividades cotidianas y son los preferidos o evitados por diversas razones (Figura 3). Este es el panorama que intentaremos trazar en este apartado. 
Figura 3

MAPA DE SÍNTESIS DE LOS ESPACIOS FRECUENTADOS, PREFERIDOS Y EVITADOS POR LOS CHICOS Y CHICAS ADOLESCENTES Y LOCALIZACIÓN DE LOS ESPACIOS DE RENOVACIÓN URBANA

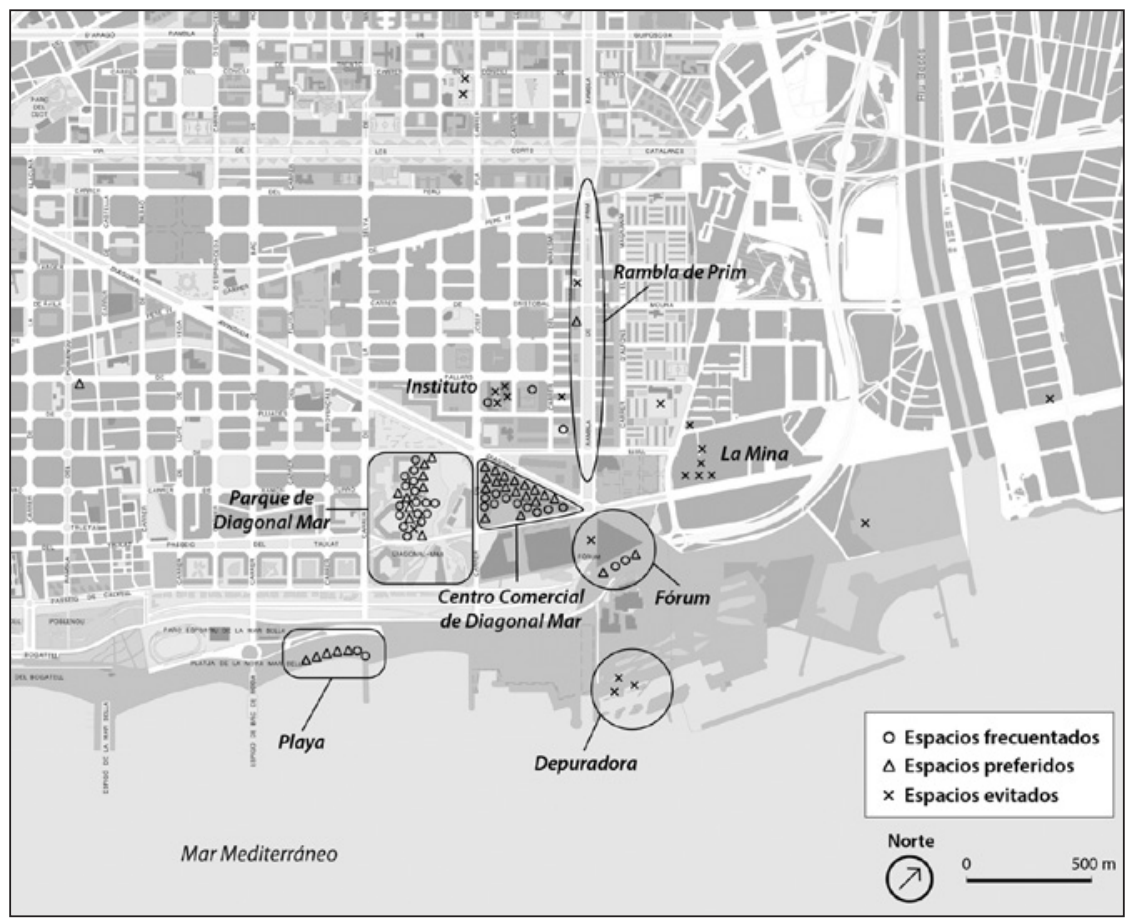

Fuente: Elaboración del mapa realizada por Alfons Parcerisas.

\section{Vivir los espacios para querer los lugares}

Antes de ver y analizar los espacios y lugares del barrio identificados por los adolescentes, vale la pena señalar las marcadas diferencias de género observadas en cuanto al tipo de actividades cotidianas de chicos y chicas en el barrio. Una de las diferencias más claras es la afición y la práctica deportiva. Las actividades deportivas y, en particular, la práctica del fútbol, emergen principal y repetidamente en el discurso de los chicos y las chicas. Se aprecia un cierto consenso al considerar la actividad deportiva y, concretamente, el fútbol, como actividades predominantemente masculinas.

«Los chicos siempre piensan en el fútbol, fútbol, fútbol... a las chicas nos gusta el fútbol pero no tanto» (Adriana).

«El mundo de las chicas en el fútbol es muy pequeño y si no eres buena, buena, buena no te conocen» (Jordi).

Beber en la calle o hacer «botellones» es citada también como una actividad más masculina que femenina (en relación con esto último José dice: «ellas pasan más de follones»). 
En cambio pasar el tiempo en el centro comercial, pasear o charlar son actividades más frecuentemente citadas como preferidas por las chicas. Así, mientras que a las chicas les gusta pasear, ir de tiendas o charlar, los chicos prefieren jugar al fútbol o ir al cibercafé y jugar con los videojuegos. Las distintas actividades que hacen en su tiempo libre contribuyen a la definición de su feminidad o su masculinidad, observándose que existen pocas prácticas o espacios para alterar esta identificación. Los estereotipos de género se translucen en sus opiniones, así mientras a las chicas se las ve como más calmadas y tranquilas, a los chicos se les ve como más activos y proclives al movimiento:

«Las chicas son más calmadas y ellos son más... (...). Todo el rato jugando a futbol o cosas de estas, hiperactivos (...). Nosotras nos sentamos y comenzamos a hablar» (Zaida).

"Al cibercafé sólo van chicos porque jugamos a juegos de estrategia, de estos de ejércitos y todo eso, y a ellas no les gusta (...). Nos vamos al ciber a hacernos una 'viciadilla' entre todos los colegas...» (José).

En conjunto los espacios públicos o de uso público preferidos, los que más frecuentan y los que más gustan tanto a chicos como a chicas adolescentes del barrio del Besós-Maresme son cuatro: el centro comercial Diagonal Mar, el parque de Diagonal Mar, el espacio del Fórum y la playa. Aunque en alguna ocasión señalan la Rambla Prim o la Rambla del Poblenou, son los espacios reurbanizados, de diseño moderno y de nueva construcción del barrio y alrededores los más citados y utilizados.

El centro comercial (Figura 4) es uno de los lugares más citados como lugar frecuentado y como lugar preferido; es donde van casi a diario, a mirar, a tocar, a probar y a veces a consumir. Les gusta porque en este lugar encuentran diversas distracciones (tiendas, bares, bolera, cines) y también pueden encontrar otros jóvenes. Allí las adolescentes miran más las tiendas de ropa y los adolescentes se fijan más en las tiendas de deportes, electrónica o de videojuegos. Su comportamiento es similar al de los adultos, pero localizar sus cuerpos en estos lugares creados y pensados para adultos representa una exploración física, una representación de su identidad y una forma de transgredir un espacio esencialmente pensado para el público adulto (probarse ropa sin intención de comprarla, maquillarse en las tiendas, entre otras exploraciones; ocasionalmente la transgresión puede ir más allá, por ejemplo, al intentar colarse en el cine).

«Me gusta el Centro comercial porque allí nos encontramos a mucha gente y en invierno no hace frío» (Chica del Grupo de discusión C).

«Al Diagonal Mar van más chicas que chicos, por eso de la ropa y tal, a los chicos no les gusta mucho (...) Al cyber, que tienen Plays de esas van todos los chicos a jugar a la Play» (Jenifer).

«Entramos en Diagonal y los chicos directamente a los juegos de la Play, de la Wii, no sé que... y a mirar estas cosas. Nosotras a veces también miramos pero también nos vamos a por los libros, la música y estas cosas. O vamos a FNAC y muchos chicos van a mirar cómics o no sé que, y yo pues voy más a la música que a los libros» (Mónica). 
Figura 4

CENTRO COMERCIAL DE DIAGONAL MAR

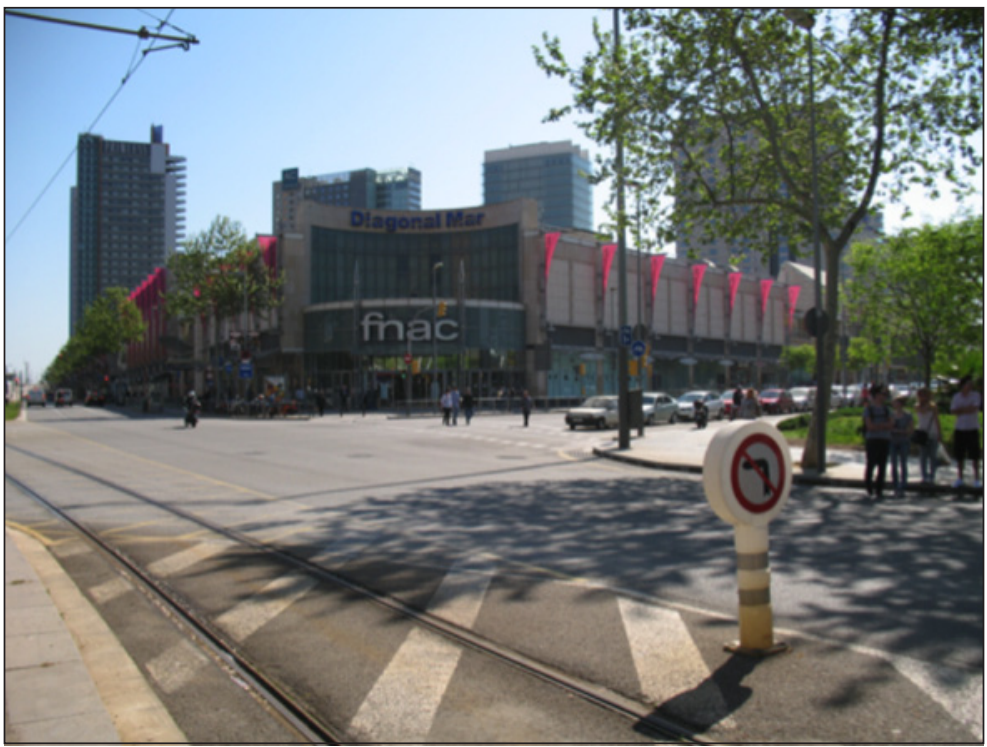

Fuente: Fotografía tomada por un chico participante.

Estos espacios de consumo se han identificado como lugares donde la gente joven se mezcla socialmente y desarrolla sus propias identidades. Además, para los y las adolescentes jóvenes con recursos económicos limitados, los centros comerciales son frecuentemente espacios contradictorios, en el sentido que representan espacios de consumo de bienes deseados que no podrán comprar porque están lejos de sus posibilidades económicas (Matthews et al., 2000). De hecho los y las adolescentes entrevistados van al centro comercial, no tanto para consumir sino para pasear, mirar escaparates, sentarse y hablar.

Un segundo espacio identificado como relevante por frecuentación y por ser percibido como grande, agradable, tranquilo y bonito es el parque Diagonal Mar (Figura 5). Este es un espacio amplio y con distintos ambientes, donde los adolescentes manifiestan sentirse a gusto, donde pueden hablar tranquilamente y expresarse con bastante libertad al ser un espacio menos frecuentado por las personas adultas del barrio, entre las que podrían encontrarse a sus familiares y sentir algún tipo de control sobre su presencia en el Parque. Les gusta también porque está muy cerca del instituto y les permite «desconectar» al ser fácilmente accesible durante las horas de recreo o a la salida.

«Me gusta porque es la zona más nueva y bonita de Barcelona» (Chica del Grupo de discusión C).

«El Parque es donde desconecto del instituto» (Chica del Grupo de discusión C).

La presencia de elementos naturales en este espacio, con elementos vegetales, plantas y árboles, el lago o incluso los insectos o los pájaros u otros pequeños animales es importante 
y son citados a la hora de valorarlo positivamente. En el Parque de Diagonal Mar hay una colina verde con unos cuantos bancos individuales, y rodeado de arbustos, lo que da la sensación de mayor recogimiento y cierta protección.

«En las colinas del Parque... allí nos sentamos toda la tarde hablando... Nos explicamos cosas, comentamos el paisaje, hacemos bromas y estas cosas» (Jenifer).

«Vamos a los toboganes, nos tiramos, hacemos un poco el burro... Nos tiramos por las montañas haciendo la croqueta... y nos vamos persiguiendo con agua... eso en verano» (Aina).

Figura 5

PARQUE DE DIAGONAL MAR

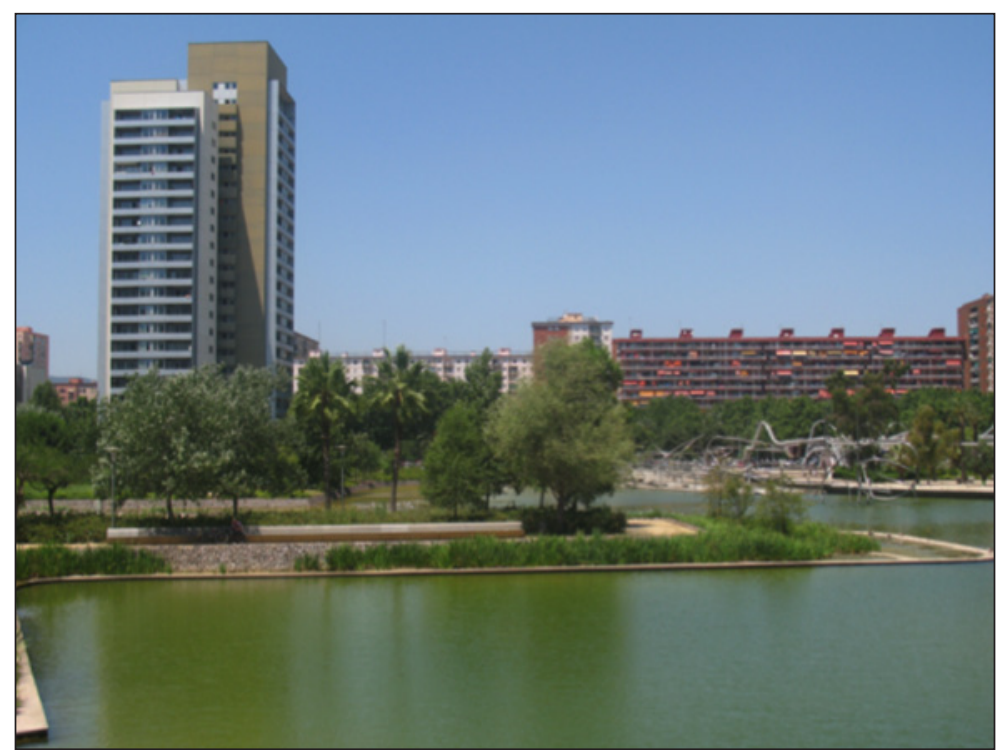

Fuente: Fotografía tomada por una chica participante.

El Fórum, un espacio cultural y de ocio multifuncional de nueva creación (Figura 6), es otro de los espacios citados en relación al tiempo de ocio, aunque menos frecuentado y generador de opiniones contrapuestas, ya que no a todos los y las adolescentes les gusta. La mayoría reconoce su monumentalidad, pero mientras para algunos resulta ser una zona tranquila y bonita, otros lo consideran un espacio vacío de contenido y desaprovechado. Aunque está presente en sus itinerarios no es un punto central en sus redes espaciales, exceptuando cuando se celebran conciertos o fiestas especiales como la Feria de Abril, que son muy apreciados.

«En el Fórum hacen muchos conciertos y también hacen feria. Y la Feria de Abril también» (Mónica). 


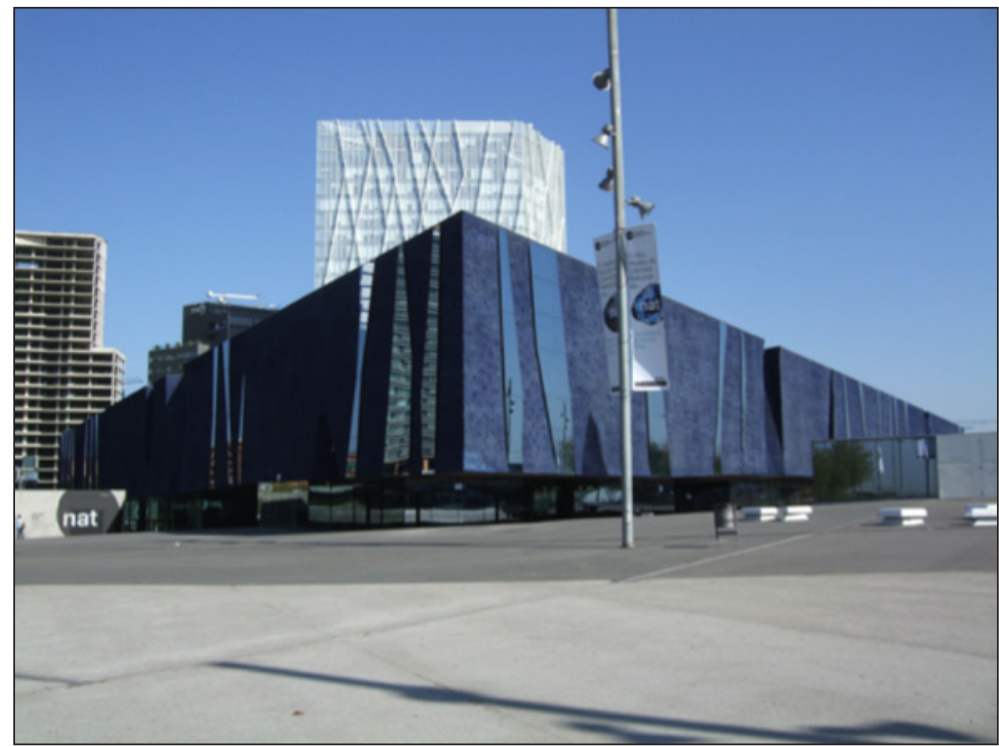

Fuente: Fotografía tomada por un chico participante.

Otro de los espacios frecuentemente citados es la playa (Figura 7), acondicionada a raíz de los últimos cambios urbanísticos en el entorno del barrio. De la playa dicen que es bonita y tranquila, relajante, un lugar donde están a gusto y que les da sensación libertad. Consideran un privilegio tener el mar y la playa tan cerca de casa o del instituto, algo que son conscientes que no ocurre en la mayoría de barrios de la ciudad y que contribuye a la visión positiva que tienen de su entorno cotidiano. La playa, tal y como ocurre con el Parque, es también percibida como un espacio de intimidad, un lugar donde poder estar sin sentirse observados por los adultos o por lo menos por los adultos de su entorno familiar.

«Vamos a la playa y nos quedamos alli hablando, nos gusta este ambiente... (...). En invierno no hay nadie, estamos nosotros solos...» (Aina).

«La playa... está muy bien, porque en verano está muy bien tener la playa aquí al lado. Y después en la playa está el espigón, unas rocas donde te sientas con tus amigas y puedes hablar tranquilamente también» (Mónica).

Sin embargo, el entorno de la playa también es al mismo tiempo objeto de críticas y percepciones ambientales negativas en cuanto a su mantenimiento, suciedad, mal olor...

«La depuradora deja el agua de la playa sucia y con mal olor» (Chica del Grupo de discusión C).

«Sí, la depuradora de agua. Es asquerosa. Huele fatal» (Chica del Grupo de discusión C). 


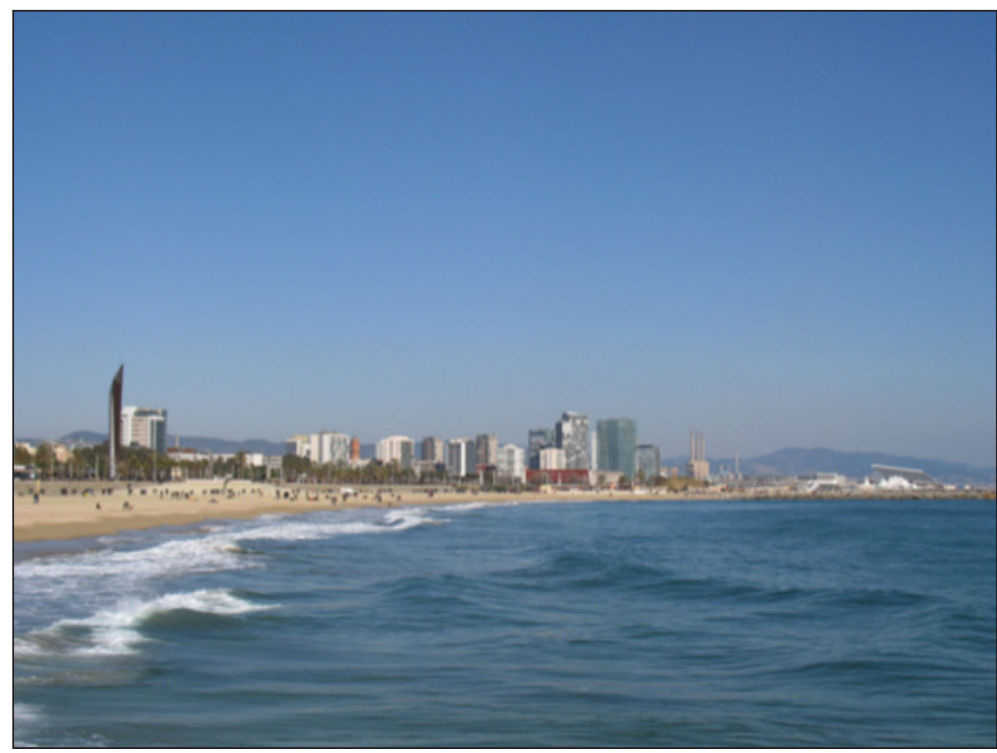

Fuente: Fotografía tomada por Anna Ortiz.

Finalmente, podemos identificar otros lugares del barrio pequeños y puntuales, que podríamos denominar microespacios personales y grupales, que adquieren relevancia por el hecho de ser lugares de encuentro, de reunión con el grupo de amigas o amigos o por ser lugares muy ligados a la historia personal de cada adolescente y especialmente por ser los lugares que mejor conocen, aquellos lugares que sienten como su propio territorio. Ejemplos de este tipo de microespacios son un determinado banco de la Rambla Prim, una determinada esquina entre calles, los portales de sus propias casas o su propia calle.

«Porque [en el Besós-Maresme] es donde me he criado y lo tengo todo, amigos... todo. Lo conozco todo» (Pablo).

«Es el lugar donde has estado toda tu infancia y tus recuerdos perduran aquí, porque has vivido parte de tu vida aquí» (Joan).

Es en esta escala más cercana donde se aprecia el amplio conocimiento del barrio, que chicas y chicos han construido a base de tiempo, a medida que han ido creciendo en el barrio. Esta es una de las principales razones por las que existen pocos espacios vetados a su cotidianeidad, cuestión que retomaremos enseguida al referirnos a los espacios evitados.

«Al vivir aquí todos los espacios del barrio me son familiares y siempre estoy a gusto» (Chica del grupo de discusión A). 
La valorización global de los adolescentes sobre los cambios urbanísticos vividos por el barrio y su entorno es positiva y ha aumentado su sentido de pertenencia al barrio. No sólo reconocen que su entorno cotidiano ha mejorado gracias a los cambios urbanísticos, sino que también sus prácticas espaciales y sus oportunidades se han visto ampliadas por las mejoras y la aparición de nuevos espacios en el barrio y su entorno. Este es un efecto positivo que, sin estar entre los principales objetivos de las operaciones urbanísticas previamente mencionadas, es una buena muestra del papel activo que indudablemente adolescentes y jóvenes tienen en los procesos de apropiación del entorno cotidiano.

«Antes el barrio estaba abandonado, era como si no fuésemos de Barcelona» (Chico del Grupo de discusión A).

«Me ha dicho mi padre que cuando yo nací o por ahí, no estaba el Diagonal y todo estaba hecho una mierda o así, y ahora lo han hecho super bien y todo eso» (Pablo).

«Si no existiesen estos lugares no saldríamos tanto a la calle»(Jenifer).

\section{Espacios inhóspitos, evitados o rechazados}

La otra cara de la moneda la constituyen los espacios que para ellos y ellas resultan inhóspitos o desagradables (por razones ambientales, como la depuradora) o aquellos espacios que, aun estando inscritos en la misma trama urbana, rechazan y evitan frecuentar. Si hablando del barrio en general hemos visto que manifiestan sentirse a gusto en todas partes precisamente porque se trata de «su barrio», hay algunas excepciones importantes en las que suelen coincidir. Un ejemplo claro, que apareció tanto en las entrevistas como en los grupos de discusión es la zona de la Mina ${ }^{13}$, así como algunas calles estrechas o descampados que les producen inseguridad. En estos casos se observa una clara diferencia de género y también cómo los y las adolescentes han aprendido a negociar el entorno y el miedo.

«Yo la verdad, no voy a la Mina, para nada, para nada porque... creo que ahí no hay nada bueno... yo prefiero estar en mi barrio» (Jordi).

«Cuando era más pequeño no me sentía seguro, pero a medida que han ido pasando los años he ido descubriendo cómo evitar las cosas, como hacer un zigzag, y me siento seguro» (Joan).

Desde el punto de vista geográfico, existe una brecha física muy significativa entre los lugares del barrio a los que los adolescentes van con sus amigos/as (y les gustan) y aquellos a los que no van (y no les gustan, pero que en cambio son lugares donde viven y estudian). Esta frontera la constituye la avenida Diagonal.

13 La Mina es un barrio de Sant Adrià del Besós, municipio que limita con Barcelona y concretamente con el barrio del Besós-Maresme. El barrio es el resultado de una actuación surgida en 1969, cuyo objetivo fue la erradicación de diferentes núcleos de «infraviviendas» en el área metropolitana de Barcelona, un proceso de construcción acelerado sin tener en cuenta la dotación de servicios finales. Actualmente, el barrio de la Mina continua estando muy estigmatizado por la alta proporción de población gitana como reflejan algunas valoraciones de las personas jóvenes entrevistadas. 
Las razones por las que determinados espacios son rechazados son variadas. Entre las chicas se expresa más claramente un rechazo a la violencia, real o percibida, que puede darse en determinadas calles o espacios y que les llevaría a evitar pasar por ellos o a frecuentar dichos lugares, aunque estas experiencias también son vividas por los chicos. Otras veces la percepción sobre un determinado lugar está marcada por una experiencia previa negativa, por haber sufrido un ataque o increpación en el espacio público. Como relata Pablo, a veces es necesario que pase cierto tiempo antes de atreverse a volver a un espacio que antes del incidente estaba entre sus lugares preferidos:

«Me pegaron una vez, una vez nos intentaron robar y salimos corriendo porque eran un montón (...) En el parque pequeño de ahí (...) Después de la experiencia estuvimos como dos meses sin ir, por eso, por el miedo... luego seguimos yendo, se nos pasó» (Pablo).

«Luego me han puesto en este instituto porque en el otro instituto siempre hay peleas, la gente se pelea en medio de las calles» (Adriana).

Nos parece importante señalar como los mismos espacios públicos pueden cambiar de significación en base a las experiencias que en ellos se viven y en base a las emociones que en ellos se experimentan. Así hemos visto como un espacio habitual y preferido puede pasar a ser rechazado a raíz de un ataque o a partir de la apropiación del espacio por parte de grupos percibidos como poco amigables o amenazantes. Por otra parte las chicas se sienten muy observadas en el espacio público. Son conscientes que su cuerpo es considerado un objeto sexual y la incomodidad, inseguridad o el miedo que les causa esa percepción ajena provoca efectos restrictivos en su uso cotidiano del espacio. Ello representa una muestra evidente de hasta qué punto la estructura patriarcal afecta a los y las adolescentes en el espacio público.

«Depende de la hora. Si es de noche o si hay una calle más estrecha por donde no pasa nadie y está más oscura, entonces sí que evito pasar y a lo mejor doy la vuelta» (Mónica).

«La adolescencia... un chico la vive de manera diferente que una chica. A lo mejor un chico puede pensar en unas cosas y la chica en otras cosas. No sé, a lo mejor un chico puede pensar más en chicas, en mujeres, eso de la sexualidad y todo eso, en tener ya relaciones sexuales y una chica pues también puede pensar en otras cosas» (Omar).

Los relatos citados son suficientes para constatar que, a pesar de la visión generalmente positiva del barrio, de sus transformaciones urbanísticas y de sus espacios públicos, hay aún margen para las mejoras, para crear nuevos espacios que respondan a necesidades no satisfechas y que ofrezcan oportunidades a ciertos colectivos que aun tienen dificultades para encontrar su lugar o compartirlo con otros. En definitiva, no sólo queda por hacer desde el punto de vista de la construcción física del espacio, sino que hay que estar atentos/as para no retroceder, para que la ciudad pueda ser vivida de forma segura y saludable y, especialmente, de forma igualitaria, porque el derecho a la ciudad es de toda la ciudadanía sea cual sea su edad, sexo u origen. 


\section{REFLEXIONES FINALES}

Este artículo es un reflejo de la voluntad de las autoras para mostrar la fuerza y la vigencia del enfoque de las geografías de la infancia y la juventud a nivel internacional, contribuyendo a este innovador enfoque con la aportación de un estudio de caso en nuestro contexto que complementa y contrasta la realidad de los países más estudiados.

El enfoque centrado en la edad y el uso de los métodos cualitativos elude directamente a unos/as interlocutores locales que a menudo son ignorados/as incluso en el urbanismo que toma en consideración la ciudadanía y los movimientos sociales. Las chicas y chicos adolescentes tienen opinión sobre su entorno y manifiestan sus propias reivindicaciones. La investigación con ellos y ellas también visibiliza una aportación conceptual interesante, la definición de «su» barrio, que no tiene porqué coincidir con la delimitación administrativa, ni con la vivencia de lo que significa el barrio para las personas adultas de la misma comunidad.

El grupo de adolescentes investigados vive en un barrio tradicionalmente periférico que en los últimos años ha vivido unos cambios urbanísticos muy significativos que han provocado importantes cambios morfológicos y sociales. Estos cambios, a pesar de la polémica que provocaron en un primer momento, han mejorado la calidad de vida de los/as adolescentes, la calidad ambiental del Besós-Maresme y ha hecho aumentar su sentido de pertenencia al barrio y a la ciudad. El espacio público es un lugar central en la vida cotidiana de los chicos y chicas adolescentes y constituyen, ya en esta etapa vital, un refugio para sus interacciones y actividades. Las aficiones y actividades realizadas en el tiempo libre por chicos y chicas coinciden con lo observado en estudios precedentes: todos/as muestran una clara preferencia por los espacios de nueva construcción, espaciosos, de diseño moderno, en fuerte contraste con las edificaciones del entorno en el que viven, más antiguas y densificadas. Prefieren estos espacios también por lo que en ellos pueden realizar, y por ser menos frecuentados por sus familiares y otras personas de la comunidad vecinal. Esto les da una tranquilidad y una privacidad que no encuentran en su entorno más inmediato. A pesar de que la edad es un factor que homogeniza en buena medida la vida urbana de los y las adolescentes, la experiencia concreta del espacio público no es neutra en cuanto al género. Las chicas, por su condición y por el rol asignado, desvelan interacciones particulares con el lugar, que se traducen, entre otras, en un uso más restringido del espacio.

El espacio público es un producto de la sociedad, por lo tanto, también de los y las adolescentes que lo viven. El uso y la apropiación que hacen cotidianamente de los nuevos espacios públicos son un ejercicio de ciudadanía ya que en ellos expresan su identidad, la negocian y la representan. Por lo tanto, su experiencia y valoración es muy importante tanto para evaluar los resultados de los proyectos urbanísticos realizados como para el diseño de los futuros.

\section{AGRADECIMIENTOS}

Queremos agradecer la inestimable ayuda del director de l'IES Besós de Barcelona, la coordinadora pedagógica y el profesorado de dicho centro. Agradecemos especialmente la disponibilidad y atención de las personas entrevistadas (adolescentes y miembros del tejido asociativo del barrio). Finalmente, también agradecemos la colaboración de las personas que han colaborado y apoyado alguna fase de la investigación. 


\section{BIBLIOGRAFÍA}

AITKEN, S. (1994): Children's Geographies. Washington D.C. Association of American Geographers

AITKEN, S. (2001): Geographies of young people: The morally contested spaces of identity. London. Routledge.

ALBERCH I FUGUERAS, R. (Dir.) (2000): Els barris de Barcelona, vol. IV en Barcelona: Enciclopèdia Catalana y Ayuntamiento de Barcelona, 264-276.

AYUNTAMIENTO DE BARCELONA (2009): «Els barris del Besòs-Maresme i La Barceloneta reben 30 milions d'euros gràcies a la Llei de Barris», Disponible en http://w3.bcn. es/fitxers/premsa/090312dossierbarcelonetamaresmebesos.009.pdf [consultado el 1 de julio de 2011].

AYUNTAMIENTO DE BARCELONA (2010): «Dades estadístiques de Barcelona», Disponible en http://www.bcn.cat [consultado el 1 de julio de 2011].

AAVV (1994): El futur de les perifèries urbanes. Canvi econòmic i crisi social a les metrópolis contemporànies, Actes de les Jornades de Reflexió i Mostra d'Art organitzades per l'Institut de Batxillerat «Barris Besòs», Barcelona, 10 al 13 de maig de 1989, Barcelona: Generalitat de Catalunya.

BAYLINA, M., ORTIZ, A. y PRATS, M. (2006): «Geografía de la Infancia. Espacios de juego en ciudades medias de Cataluña». Geographicalia, $n^{\circ}$ 50, 5-26.

BLACKFORD, Holly (2004). «Playground panopticism. Ring-around-the children, a pocketful of women». Childhood, vol. 11, n 2, 227-249.

BORATAV, H. B. (2005): «Negotiating youth: Growing up in inner-city Istanbul». Journal of Youth Studies, vol. 8, n 2, 203-220.

BORJA, J. (2010): Luces y sombras del urbanismo de Barcelona, Barcelona, Editorial UOC.

BOTELLA, M. (2006): El Fòrum Barcelona 2004. Una oportunitat desaprofitada, Barcelona: Aula Barcelona y Universitat de Barcelona, Quaderns de gestió, 19. http://www. aulabarcelona.org/php/quaderns_gestio.php

BUNNELL, T., YEA, S., PEAKE, L., SKELTON, T. y SMITH, M. (2011): «Geographies of friendships». Progress in Human Geography, Vol. 36, n 4, 490-507.

CAHILL, C. (2000): «Street literacy: Urban teenagers' strategies for negotiating their neighbourhood». Journal of Youth Studies, vol. 3, n 3, 251-277.

CIA, B. (2002): «Un parque para dos caras de la Diagonal». El País, 21 de septiembre de 2002.

CHURCHMAN, A. (2003): «Is there a place for children in the city?». Journal of Urban Design, vol. 8, $\mathrm{n}^{\circ} 2,99-111$.

DOMÈNECH, Ll. (2006): Barcelona un quart de segle d'urbanisme (1979-2004). Barcelona: Aula Barcelona y Universitat de Barcelona. Quaderns de Gestió, 21.

DRISKELL, D., FOX, C. y KUDVA, N. (2008): «Growing up in the new New York: Youth space, citizenship and community change in hyper global city». Environmental Planning $A$, vol. 40, 2831-2844.

EHRKAMP, P. (2008): «Risking publicity: masculinities and the racialization of public neighbourhood space». Social \& Cultural Geography, vol. 9, nº 2, 117-133. 
EVANS, R. (2006): «Negotiating social identities: The influence of gender, age and ethnicity on young people's 'street careers' in Tanzania». Children'sGeographies, vol. 4, n 1 , 109-128.

FABRÉ, J. y HUERTAS, J.M. (1977): Tots el barris de Barcelona (VII). Barcelona. Edicions 62.

GIRÓ, J. (2011): «Las amistades y el ocio de los adolescentes hijos de la inmigración». Papers, vol. 96, $\mathrm{n}^{\circ}$ 1, 77-95.

GOUGH, K.V. y FRANCH, M. (2005): «Spaces of the street: Socio-spatial mobility and exclusion of youth in Recife». Children's Geographies, vol. 3, n 2, 149-166.

HOLlOWAY, S. y VALENTINE, G. (2000): Children's geographies: Playing, living and learning. London. Routledge.

HOLLOWAY, S., HUBBARD, P., JÖNS, H. y PIMLOTT-WILSON, H. (2010): «Geographies of education and the significance of children, youth and families». Progress in Human Geography, vol. 34, n 5, 583-600.

HOLLOWAY, S., BROWN, G. y PIMLOTT-WILSON, H. (2011). «Editorial introduction: Geographies of education and aspiration», Children's Geographies, vol. 9, nº1, 1-5.

HÖRSCHELMANN, Kathrin y van BLERK, Lorraine (2011): Children, youth and the city. London. Routledge.

HYAMS, M. (2003): «Adolescent Latina bodyspaces: Making home girls, home bodies and home places». Antipode, $\mathrm{n}^{\circ} 35,535-558$.

INDYMEDIA BARCELONA (2004): «Balance de la asamblea de resistencias al Fórum» Disponible en http://barcelona.indymedia.org/newswire/display/122526/index.php [consultado el 16 de enero de 2012].

KARSTEN, L. (2003): «Children's use of public space: the gendered world of the playground». Childhood, vol. 10, $\mathrm{n}^{\circ}$ 4, 457-473.

KATO, Y. (2009): «Doing consumption and sitting cars: adolescent bodies in suburban commercial spaces». Children's geographies, vol. 7, $\mathrm{n}^{\circ} 1,51-66$.

KATZ, C. (2006): «Los terrores de la hipervigilancia: seguridad y nuevas espacialidades de la niñez». Documents d'Anàlisi Geogràfica, nº 47, 15-29.

LIESHOUT, M. van y AARTS, N. (2008): «Youth and immigrants' perspectives on public space». Space and Culture, $\mathrm{n}^{\circ}$ 11, 497-513.

MATTHEWS, H. (1995): «Living on the edge: children as 'outsiders'». Tijdschrift voor Economische en Sociale Geografie, vol. 86, nº 5, 456-466.

MATTHEWS, H. (2001): «Citizenship, youth councils and young people's participation». Journal of Youth Studies, vol. 4, nº 3, 299-318.

MATHEWS, H. (2003): «Coming of age for children's geographies». Children's Geographies, vol. 1, $\mathrm{n}^{\mathrm{o}}$ 1, 3-5.

MATTHEWS, H.; TAYLOR, M.; PERCY-SMITH, B.; y LIMB, M. (2000): «The unacceptable Flaneur: the shopping mall as a teenage hangout». Childhood, vol. 7, n 3, 279-94.

MCKENDRICK, J.H. (2000): «The geography of children. An annotated bibliography». Childhood, vol. 7, no 3, 359-387.

MORRIS-ROBERTS, K. (2001): «Intervening in friendship exclusion? The politics of doing feminist research with teenage girls». Ethics, Place and Environment, vol. 4, no 2, 147-153.

MORRIS-ROBERTS, K. (2010): «Girls' friendships, 'distinctive individuality' and sociospatial practices of (dis)identification». Children's Geographies, vol. 2, nº 2, 237-255. 
ORTIZ, A. (2007): «Geografías de la infancia: descubriendo nuevas formas de ver y entender el mundo». Documents d'Anàlisi Geogràfica, no 49, 197-216.

PRATS, M. (2010): «Una revisió crítica de la recerca sobre geografies de la infància en el context de l'Àfrica subsahariana». Documents d'Anàlisi Geogràfica, vol. 57, nº 1, 127 146.

RABY, R.C. (2002): «A tangle of discourses: Girls negotiating adolescence». Journal of Youth Studies, vol. 5, no 4, 425-448.

RECIO, A. (2008): «Les desigualtats econòmiques i els barris», en La Barcelona dels barris. Barcelona. Federació d'Associacions de Veïns i Veïnes de Barcelona (FAVB), 187-199.

REYNOLDS, T. (2007): «Friendship networks, social capital and ethnic identity: Researching the perspectives of Caribbean young people in Britain». Journal of Youth Studies, vol. $10, n^{\circ} .4,383-398$.

RODÓ-DE ZÁRATE, M. (2010): «El jovent i els espais públics urbans des d'una perspectiva de gènere». Documents d'Anàlisi Geogràfica, vol. 57, nº 1, 147-162.

SKELTON, T. (2011): «Adult anxieties versus young people's resistance. Negotiating access to public space in Singapore», en Geographies of Children, Youth and Families. An International Perspective (Holt, L., ed.). London. Routledge, 203-220.

THOMAS, M. E. (2005): «Girls, consumption space and the contradictions of hanging out in the city». Social \& Cultural Geography, vol. 6, n 4, 587-605.

VALENTINE, G. (2004): Public space and the culture of childhood. Hants. Ashgate.

VANDERSTEDE, W. (2011): «Chilling and hopping in the teenage space network: explorations in teenagers' geographies in the city of Mechelen». Children's Geographies, vol. 9, $\mathrm{n}^{\mathrm{o}} 2,167-184$.

WARD, C. (1978): The child in the city. London. Bedford Square Press.

WELLER, S. (2006): «Situating (young) teenagers in geographies of children and youth». Children's Geographies, vol. 4, nº 1, 97-108. 
